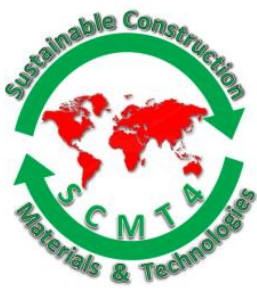

SCMT4

Las Vegas, USA, August 7-11, 2016

\title{
Sustainability Assessment of Cements and Concretes in the Indian Context: Influence of Supplementary Cementitious Materials
}

\author{
Ravindra Gettu ${ }^{1 \mathrm{a}}$, Aanchal Patel ${ }^{1 \mathrm{~b}}$, Vaibhav Rathi ${ }^{2 \mathrm{a}}$, Sanoop Prakasan ${ }^{1 \mathrm{c}}$, \\ Anusha S. Basavaraj ${ }^{1 d}$, and Soumen Maity ${ }^{2 b}$
}

${ }^{I}$ Dept. of Civil Engineering, Indian Institute of Technology Madras, Chennai 600036, INDIA.

${ }^{2}$ Development Alternatives, B-32 TARA Crescent, Qutub Instnl. Area, New Delhi 110016, INDIA.

${ }^{1 a}$ Email: <gettu@iitm.ac.in>, ${ }^{1 b}$ Email: <aanchal.patel70@gmail.com>,

${ }^{2 a}$ Email: <vrathi@devalt.org>, ${ }^{1 c}$ Email <sanoop.prakasan@gmail.com>,

${ }^{1 d}$ Email <anushabasavaraj@gmail.com>, ${ }^{2 b}$ Email <smaity@devalt.org>.

\begin{abstract}
Considering that India is the second largest producer and consumer of cement in the world, it is understood that its production and use has a tremendous impact on the energy consumption and carbon dioxide emissions. More than $75 \%$ of cement in India is made by blending ground clinker with fly ash, ground granulated blast furnace slag, limestone or other supplementary cementitious materials (SCMs). Further, there have been only limited studies on the sustainability assessment of cement and concrete that can give a clear picture of the impact and help mitigate it in future. The work presented here is based on realistic process maps made in cement plants and data collected from them. The concretes assessed are based on two typical strength grades obtained with blended cements, as well as only portland cement. The results highlight the importance of the SCMs in terms of total energy consumption and carbon dioxide emissions. The study also draws attention to the need to use high grades of concrete to better harness the benefits of the SCMs. Further, the need to generate more relevant data sets for the Indian context is recognized.
\end{abstract}

\section{INTRODUCTION}

The consumption of cement in India is about 280 million tonnes per year, which is the second highest in the world, after China. Considering that that the per capita cement use is about $190 \mathrm{~kg}$ and can reach about $350 \mathrm{~kg}$ eventually, the cement production is expected to surpass 500 million tonnes by 2025 [IBEF 2016]. Since there is also a major push for the infrastructure spending and housing development, the cement and concrete production can be expected to have a major impact on the energy demand and green house gas emissions. Further, there will be a lot of pressure on the already limited raw materials and fuels. The first step in the assessment of the sustainability is the ability to have a framework and benchmarks for the calculations of energy consumption and $\mathrm{CO}_{2}$ emissions that are relevant to the Indian context. The present work is an attempt in using existing data sets appropriately to estimate the benefits of using supplementary cementitious materials (SCMs) in cement and concrete. 
In addition to assessing cements with fly ash and ground granulated blast furnace slag (GGBS), a newly proposed binder called limestone calcined clay cement or $\mathrm{LC}^{3}$, having $50 \%$ clinker, $30 \%$ calcined China clay (with a typical kaolinite content of 50-60\%), 15\% crushed limestone and 5\% gypsum has also been studied. The clay was mined in lumps, and processed with a jaw crusher and disintegrator into particles of less than $5 \mathrm{~mm}$ in size. The clay was later calcined at a temperature of around $800{ }^{\circ} \mathrm{C}$ in a rotary calciner and was air quenched to room temperature. This was precrushed along with cement clinker and limestone before being ground in a closed circuit type ball mill. This binder has been produced for experimental purposes by IIT Delhi and Development Alternatives as part of a project on low carbon cement.

The impact of $\mathrm{LC}^{3}$ is compared with that of the reference cements in order to assess the role of the nonclinker component of the cements. The system considered is cradle-to-gate or ground-to-gate (more appropriate for products that rely heavily on mined resources) and applied to a typical cement plant location in South India. In addition to assessing the cements, typical concretes of 30 and $50 \mathrm{MPa}$ design strengths are evaluated using mixture proportions obtained in the laboratory for the different binder systems. The framework for both the assessments, as well as some peculiar aspects of the Indian construction sector, that are relevant for the sustainability analysis are discussed.

\section{ISSUES RELEVANT TO THE INDIAN CONTEXT}

There are several factors, traditions and trends related to cement in India that have major repercussions on sustainability. Some of the important ones are discussed here.

\section{Ecology or Environmental Impact}

- Considering that India relies heavily on coal for the thermal energy required for clinkerization and electricity production, there is considerable significance of the energy-related processes to the environmental impact. Further, in this context, the replacement of fossil fuel generated energy with electricity does not necessarily result in more eco-friendliness unless alternative energy sources (i.e., solar, wind) are harnessed for producing electricity, in a major way.

- For now, among the different options available for construction, cement-based materials, especially concrete, have the least embodied energy or $\mathrm{CO}_{2}$ emission [Barcelo et al. 2014, Scrivener 2014].

- Waste heat from kiln exit gases is not always recovered; it is estimated that $30-40 \%$ of input heat energy is released as waste [Rajya Sabha Secretariat 2011].

- Non-uniform emission standards permit higher levels of pollution in smaller cement plants [Rajya Sabha Secretariat 2011], which may not also have efficient monitoring systems or stringent protocols in place.

\section{Economy}

- Unreliable power supply from the grid has increased the dependence on captive power generation, which adds to the costs [Rajya Sabha Secretariat 2011].

- Recovery of waste heat and co-generation of power requires costly installations [Rajya Sabha Secretariat 2011].

- Regulated coal supply in India is limited so the more expensive use of imports and pet coke is necessitated [Rajya Sabha Secretariat 2011].

- Possibility of cartelisation exists as only few groups control $60 \%$ or more of the cement production [Rajya Sabha Secretariat 2011], which could lead to higher than normal expenses for the consumer.

- Companies expect to recover capital expenditure over short terms, such as 3-7 years, which limits investment for sustainability. 
- Financial aid to the States is not linked well with pollution reduction, and incentives to plants that are more eco-friendly are poor [Rajya Sabha Secretariat 2011].

\section{Social Issues and Concerns}

- The public, in general, are not aware of the norms [Rajya Sabha Secretariat 2011] related to environmental protection and taxation. So, social pressure on the sector is not leveraged for improvement to happen.

- Construction industry favours fast setting and high early strength cement even though most applications do not require high strengths, which results in higher energy requirements for grinding and clinkerization, more curing water and superplasticizers, and less potential for using poorer grade limestone and lower clinker contents.

- The project owner (especially in housing) often decides the brand of cement to be used, and is influenced by advertising of strength and the colour. This limits the risk that can be taken by cement companies for introducing new materials.

- Many specifications only permit ordinary portland cement (OPC) for major infrastructure and other public projects. This prevents the use of more eco-friendly blended cements.

\section{CEMENT MANUFACTURE AND USAGE: INDIAN SCENARIO}

The production of cement, more precisely the clinker, in India is mostly in four limestone-rich belts that also have good accessibility to facilitate the transportation of coal. Most cement production is done in integrated plants that produce clinker as well as cement. However, there are several grinding units, the number of which is expected to increase, that obtain clinker from the integrated plants and grind it, and blend with gypsum and other components to make cement. About $70 \%$ or more of the cement produced in India is bagged for sale and the rest is transported in bulkers to major construction sites.

Fly ash is extensively used in cement and concrete manufacture in India as it is abundantly available since about $70 \%$ of the electricity in India is derived from burning coal [CEA 2015]. Portland pozzolana cement, containing $25-35 \%$ of Class F fly ash, makes up about $67 \%$ of the cement produced. Further, it is common for ready mixed concrete to be made with $15-30 \%$ of fly ash, by weight of cement. Fly ash was initially supplied to the cement companies free of cost but it is now recognized by the Government as a saleable commodity [Rajya Sabha Secretariat 2011]. Therefore, the economics of fly ash usage in concrete in India are changing. Cement grinding units are often located close to thermal power plants to reduce the transportation costs of fly ash.

Ground granulated blast furnace slag (GGBS) is used in the order of about 8 million tonnes in the manufacture of portland slag cement (PSC), which contains 30-50\% of GGBS; PSC makes up about 8\% of the cement produced in India [Rajya Sabha Secretariat 2011]. Some GGBS is also used in ready mixed concrete production located close to steel plants. It is not uncommon to have steel manufacturing groups market GGBS or even manufacture PSC though their subsidiaries. This has repercussions on the costs and availability.

There are other SCMs used in cement and concrete in India, such as crushed limestone, metakaolin, silica fume and Class $\mathrm{C}$ fly ash. However, their relevance is limited.

A new alternative proposed for blended cement in India is limestone calcined clay cement $\left(\mathrm{LC}^{3}\right)$, where the clinker factor could be as low as 50\% [Bishnoi et al. 2014, Scrivener 2014]. This blended cement type is promising since India has abundant deposits of clay, and there are large quantities of waste clay from the ceramic industries. The fabrication of such cement could especially be viable where limestone is of 
poor quality or scarce, and there are no thermal power plants in the vicinity. The scenarios proposed range, on the one hand, from the conventional integrated plant setting up a calcination unit for treating local clay and blending it to give the $\mathrm{LC}^{3}$ to, on the other hand, having the grinding unit procure clinker and calcined clay for making the cement.

Further, the assessment of cement production in India should also consider the following:

- The raw material input in the clinker is often dominated by limestone, without much input of other materials such as clay, marl, shale, etc., which are common elsewhere.

- Limestone mines are directly managed by the cement companies and the clinkerization units are located near the mines. Therefore, there is little wastage of limestone since the composition of the raw meal is optimized by mixing different qualities of limestone. Further, transportation between the mines and the plant is minimal.

- Most Indian clinkerization units use the dry process so the process water [Marceau et al. 2006] and overall water consumptions of cement are low.

- Electricity in India is produced mostly (70\% or more) by burning coal. Therefore, the use of electricity does not necessarily lead to lower impact unless it is generated by alternative sources in the plant or elsewhere.

- Phosphogypsum, a waste product from the fertilizer industry, is used to a large extent instead of natural gypsum.

- There is substantial use of industrial waste and biomass as alternative fuels; in some plants, as much as $10 \%$ of the energy requirement is met through alternative fuels.

Therefore, it is necessary that an inventory be compiled for typical plants in India so that conclusions regarding the industry can be made more reliably. However, this is not easy or even feasible most of the time. In the present study, an available inventory and conversion factors are used as appropriate. In the compilation of the inventory data and the subsequent life cycle assessment (LCA), it is of utmost importance to define the system boundaries unambiguously so that it is clear what impacts are included and excluded. Here, the ground-to-gate system is considered, where all impacts from the mines to the gate of the cement plant are accounted for. The energy requirements and $\mathrm{CO}_{2}$ emissions (direct and indirect) are considered from all processes involved in the production of cement, including the extraction and transportation of all fuels and raw materials, and the production of electricity. However, the energy and emissions associated with alternative fuel and fly ash are excluded. This system gives a complete (though academic) assessment in accordance with most scientific literature. However, most assumptions and conversions may not be ideal for Indian conditions and materials, which warrant further refinement in the future. Nevertheless, the values obtained are used here for a relative assessment so the conclusions are not affected by the approximations made.

\section{LIFE CYCLE ASSESSMENT OF TYPICAL CEMENTS IN THE INDIAN CONTEXT}

In order to illustrate the methodology, a typical integrated cement plant in the region of Ariyalur, Tamil Nadu, India, which has rich limestone deposits, was chosen for this study. The plant studied has been leased limestone quarries adjacent to it. Since the limestone is soft in this region, it is extracted by excavation without blasting, and has an average composition with about $44 \% \mathrm{CaO}, 12.5 \% \mathrm{SiO}_{2}, 10 \%$ moisture and $35.5 \%$ loss on ignition. For the PPC, the Class F Fly ash is transported from the Mettur Power Plant (200 km), with a composition of $61 \% \mathrm{SiO}_{2}, 27 \% \mathrm{Al}_{2} \mathrm{O}_{3}$ and $4 \% \mathrm{Fe}_{2} \mathrm{O}_{3}$, and incorporated at $30 \%$ by weight of PPC. Phosphogypsum transported from Tutticorin $(385 \mathrm{~km})$ is used in the cement. It is assumed that PSC would be made with GGBS transported from Nandyal $(550 \mathrm{~km})$ and incorporated at $50 \%$ by weight of the cement. It is also assumed that the clay will be sourced from Dharmapuri (104 km away), and transported to and calcined at the cement plant. The composition considered for the $\mathrm{LC}^{3}$ is $50 \%$ clinker, $30 \%$ calcined clay, $15 \%$ crushed limestone and 5\% gypsum. 
Following the principles outlined in the previous section, the energy and $\mathrm{CO}_{2}$ emissions were computed for OPC, PPC, PSC and $\mathrm{LC}^{3}$ as if they were fabricated in the same plant. The SimaPro software (PRé Consultants 2016) has been used for performing the LCA, with the allocation default unit processes of the ecoinvent 3 data set [ecoinvent Centre 2016]. The $\mathrm{CO}_{2}$ emissions are determined using the IPCC 2013 GWP 100a [Garg et al. 2007] and embodied energy from the cumulative energy demand conversion factors given in SimaPro. It is considered, based on actual plant data, that the material consumption for one tonne of clinker includes: $1447 \mathrm{~kg}$ of limestone, $63 \mathrm{~kg}$ of clay, $36 \mathrm{~kg}$ of lignite, $1 \mathrm{~kg}$ of hard coal, 0.04 $\mathrm{kg}$ of diesel, $60 \mathrm{~kg}$ of petroleum coke, and $17 \mathrm{~kg}$ of biomass and alternative fuel, in addition to $53 \mathrm{kWh}$ of electricity. The calcination energy for clay has been taken as $2.6 \mathrm{GJ} /$ tonne, which is a highly conservative estimate, and it has been assumed that calcination will be done using same components of fuel as used in the clinkerization. The fly ash and gypsum are taken as waste products and so only their transportation is considered for the LCA. The results of the assessment are given in Table 1.

Table 1. Impacts of the different cements considered

\begin{tabular}{|l|c|c|c|c|}
\hline Impact & OPC & PPC & PSC & LC $^{3}$ \\
\hline Energy consumed, GJ/tonne & 2.86 & 2.32 & 4.67 & 2.56 \\
\hline $\mathrm{CO}_{2}$ emission, kg/tonne & 870 & 660 & 730 & 590 \\
\hline
\end{tabular}

It appears that the values obtained here, especially for OPC, are much lower than expected; Hammond and Jones [2008] give an embodied energy of $3.3 \mathrm{GJ} /$ tonne for dry kiln manufactured portland cement, and other estimates give values as high as $3.8 \mathrm{GJ} /$ tonne in Indian conditions. However, the $\mathrm{CO}_{2}$ emissions seem to compare well with the literature [e.g., Barcelo et al. 2014]. Nevertheless, as already stated, the energy values can vary considerably due to the conversion factors used. The reason for PSC having a high impact is that the cumulative energy demand for GGBS (including the processes of quenching/granulation, crushing, grinding and storage in silos) in SimaPro is $5.1 \mathrm{GJ} /$ tonne while for clinkerization it is $2.43 \mathrm{GJ} /$ tonne of clinker. This can be due to the attribution of a significant part of the energy required for the steel making processes to the slag as it is a major saleable by-product. The low clinker factor in $\mathrm{LC}^{3}$ gives it a much lower impact than OPC and PSC, though in terms of energy requirement it gives a higher value than PPC.

\section{LIFE CYCLE ASSESSMENT OF CONCRETES IN THE INDIAN CONTEXT}

For the LCA of concrete, there are several approaches to make comparisons to account for the change in performance due to the different cements and concrete composition [e.g., Miller et al. 2015]. However, the most important performance parameter for the construction industry is the compressive strength, and India is no exception. Consequently, concretes of the same 28-day compressive strengths made with different SCMs (same as those considered in the cement assessment) were assessed. Two grades of concretes are considered as made in Chennai, with 30 and $50 \mathrm{MPa}$ design compressive strengths, designated as M30 and M50, respectively. Trials in the laboratory at IIT Madras have yielded the mix proportions given in Tables 2 and 3 for the different binder systems. The fine aggregate is river sand and the coarse aggregate is crushed granite.

Table 2. Mix proportions for the M30 concrete (per $\mathbf{~ m}^{3}$ )

\begin{tabular}{|l|c|c|c|c|}
\hline Component $(\mathrm{kg})$ & OPC & OPC $+30 \%$ fly ash & OPC + 15\% GGBS & LC $^{3}$ \\
\hline Binder & 310 & 310 & 310 & 310 \\
\hline Water & 159 & 142 & 186 & 155 \\
\hline Coarse aggregate & 1222 & 1232 & 1255 & 1222 \\
\hline Sand & 706 & 716 & 649 & 715 \\
\hline
\end{tabular}


Table 3. Mix proportions for the M50 concrete (per $\mathbf{~ m}^{3}$ )

\begin{tabular}{|l|c|c|c|c|}
\hline Component $(\mathrm{kg})$ & OPC & OPC $+30 \%$ fly ash & OPC + 15\% GGBS & LC $^{3}$ \\
\hline Binder & 360 & 380 & 310 & 340 \\
\hline Water & 144 & 133 & 155 & 136 \\
\hline Coarse aggregate & 1193 & 1188 & 1275 & 1220 \\
\hline Sand & 703 & 699 & 660 & 704 \\
\hline
\end{tabular}

For the LCA, it is considered that the cement (OPC or $\mathrm{LC}^{3}$ ) is brought to Chennai from Ariyalur $(307 \mathrm{~km})$, sand from Villupuram $(192 \mathrm{~km})$, crushed granite coarse aggregate from Kanchipuram $(75 \mathrm{~km})$, and GGBS from Nandyal $(400 \mathrm{~km})$. Further, it is assumed that the impact of the superplasticizer is negligible as it accounts for less than $1 \%$ by mass of the concrete, only one-way trips of loaded trucks are to be considered for transportation process, and electricity only from the grid is utilized.

The results of the energy consumption calculations are shown in Figures 1 and 2, respectively, for M30 and M50 concretes. The values seem to be in the ranges reported in the literature; e.g., Hammond and Jones [2008] give embodied energies of $0.95-1.1 \mathrm{MJ} / \mathrm{kg}$ in good quality concretes. The binder, transportation and electricity dominate the embodied energy. With the latter two sources being similar, the variations are basically due to the binder characteristics. It is evident that the benefits of SCM incorporation are more in higher grade concretes. Considering that such concretes will also have better durability, a strong case is made for the use of higher grade concretes in construction. LC $^{3}$ gives an impact comparable with the OPC $+30 \%$ fly ash binder system.

The results of the equivalent $\mathrm{CO}_{2}$ emissions are shown in Figures 3 and 4, respectively, for M30 and M50 concretes. These values are also in the ranges reported in the literature; e.g., Flower and Sanjayan [2007] gave values of about $0.13 \mathrm{~kg} / \mathrm{kg}$ for OPC concrete, and the embodied carbon values given by Hammond and Jones [2008] yield $\mathrm{CO}_{2}$ of $0.13-0.16 \mathrm{~kg} / \mathrm{kg}$. The plots indicate that more than $75 \%$ of the $\mathrm{CO}_{2}$ emissions associated with concrete can be attributed to the cement, when only OPC is used. Transportation and electricity account for a sizeable part of the rest. This is in accordance with the findings of other researchers, such as Flower and Sanjayan [2007], and Marceau et al. [2007]. The major component of the emissions reduces significantly when OPC is replaced with a blended binder. It is seen that the use of fly ash and GGBS decreases the $\mathrm{CO}_{2}$ emissions by about $22 \%$ and $6 \%$ in the M30 concrete, and by about $26 \%$ and $21 \%$ in the M50 concrete. These trends are in accordance with the ranges seen by Flower and Sanjayan [2007]. The $\mathrm{LC}^{3}$ concretes are very promising in terms of $\mathrm{CO}_{2}$ emissions, with a 30$35 \%$ reduction compared to OPC concretes of the same compressive strengths.

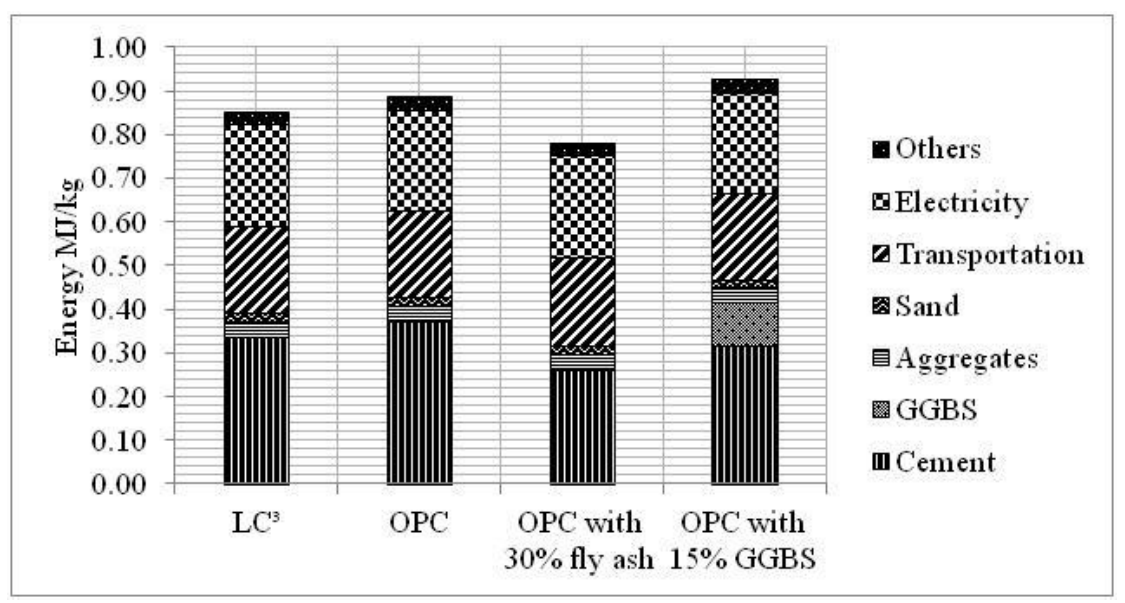

Figure 1. Energy consumption for M30 concrete 


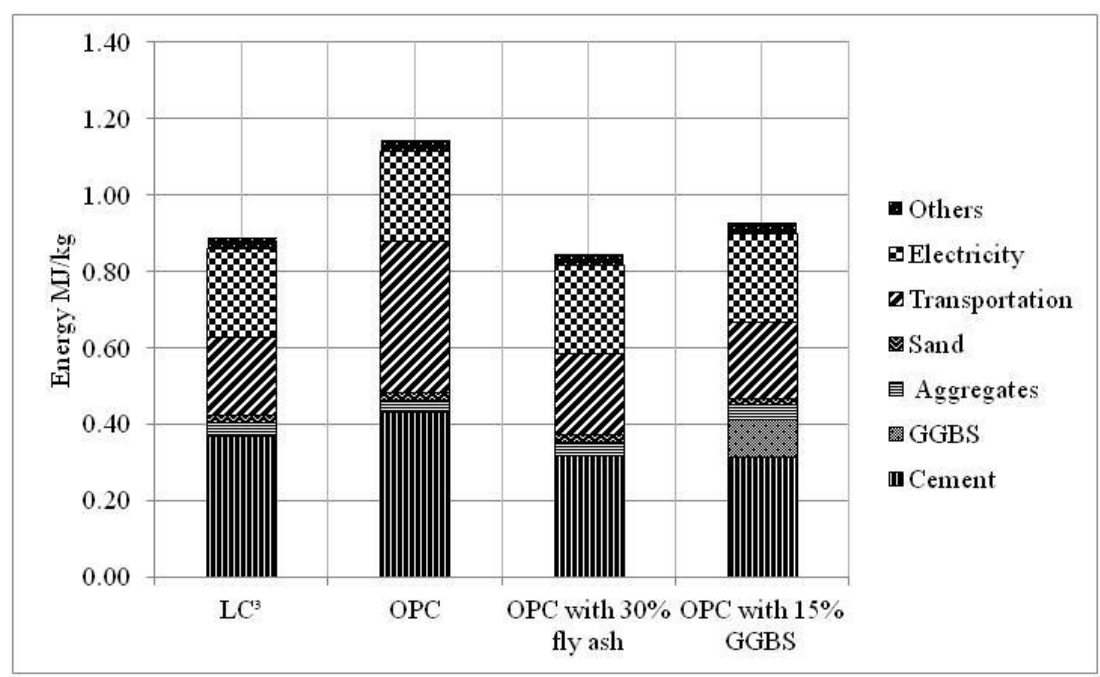

Figure 2. Energy consumption for M50 concrete

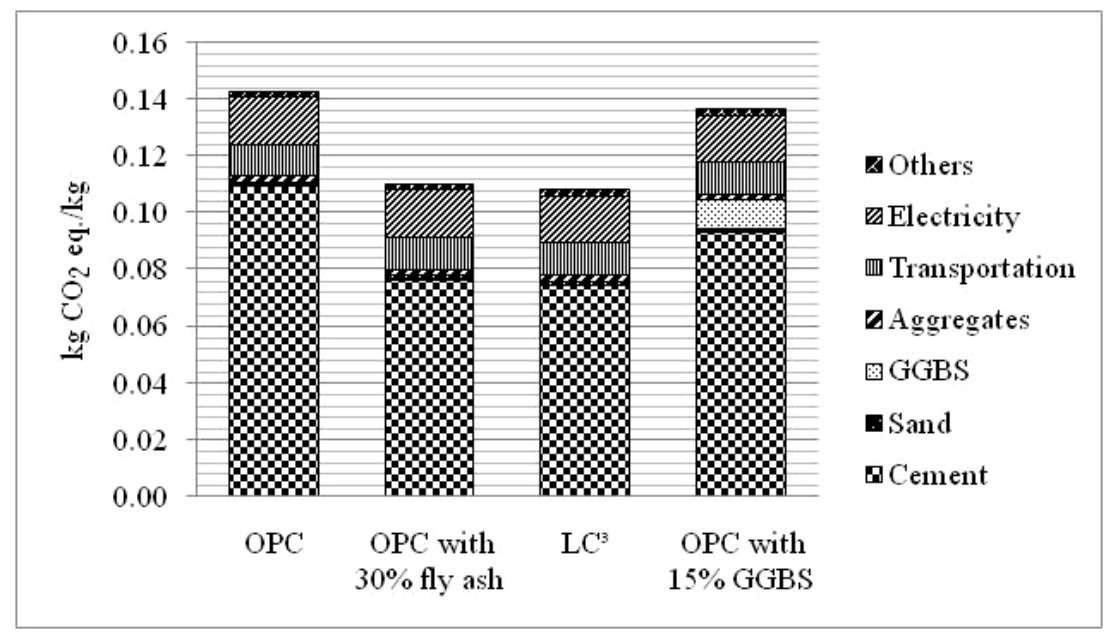

Figure 3. $\mathrm{CO}_{2}$ emissions for $\mathrm{M30}$ concrete

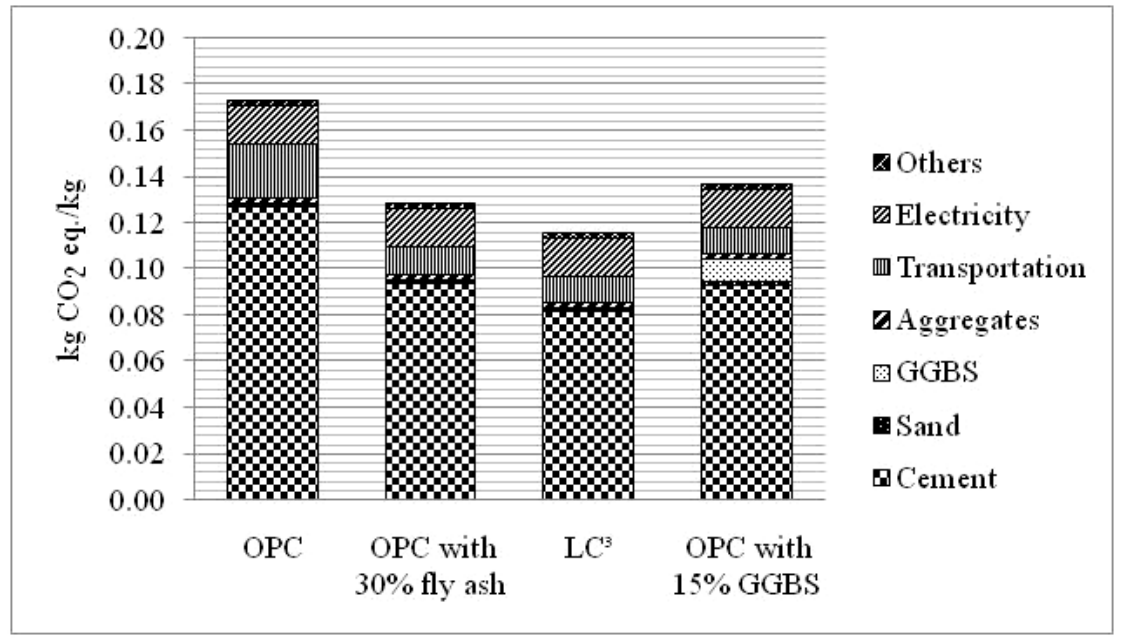

Figure 4. $\mathrm{CO}_{2}$ emissions for $\mathrm{M50}$ concrete 


\section{CONCLUSION}

The life cycle assessment of cement and concrete in the Indian context has been carried out by appropriately adapting existing data bases and conversion factors. Though some aspects may not be relevant to the local conditions, the results seem reasonable. They confirm that the use of supplementary cementitious materials lead to substantial benefits in terms of energy consumption and $\mathrm{CO}_{2}$ emissions. However, the use of GGBS at a dosage of $15 \%$ is not as beneficial as the incorporation of fly ash at $30 \%$. This is attributed to energy required to process the slag, which is not treated as a waste product such as fly ash. The newly proposed limestone calcined clay cement $\left(\mathrm{LC}^{3}\right)$, with a clinker factor of $50 \%$, is seen to be considerably beneficial for impact reduction, even though a conservative calcination energy value has been used. The assessment indicates that $\mathrm{LC}^{3}$ has a promising future in the India. It is also evident that the benefits of using SCMs are significantly more in higher grade concretes.

\section{ACKNOWLEDGEMENTS}

The authors are grateful for partial funding from the Swiss Agency for Development and Cooperation through the project on Low Carbon Cement (ref. 7F-0857.01.02) with the École Polytechnique Fédérale de Lausanne. The suggestions and help given by Profs. Karen Scrivener (EPFL), Guillaume Habert (ETHZ), Sivakumar Palaniappan (IITM) and Shashank Bishnoi (IITD) are sincerely appreciated. The mix designs of the concretes were done by T. Sakthivel and B.S. Dhanya at IIT Madras.

\section{REFERENCES}

Barcelo, L., Kline, J., Walenta, G., and Gartner, E. (2014). "Cement and carbon emissions", Materials and Structures, 47, 1055-1065.

Bishnoi, S., Maity, S., Mallik, A., Joseph, S., and Krishnan, S. (2014). "Pilot scale manufacture of limestone calcined clay cement: The Indian experience", Indian Concrete J., 88(7), 22-28.

CEA (2015). Report on Fly Ash Generation at Coal/Lignite Based Thermal Power Stations and Its Utilization in the Country for the Year 2014-15, Central Electricity Authority, New Delhi, 2015.

Ecoinvent Centre. http://www.ecoinvent.org (accessed 31st Jan. 2016).

Flower, D.J.M., and Sanjayan, J.G. (2007). "Green house gas emissions due to concrete manufacture", Int. J. LCA, 12(5), 282-288.

Garg, A., Kazunari, K., and Pulles, T. (2007). 2006 IPCC Guidelines for National Greenhouse Gas Inventories, http://www.ipcc-nggip.iges.or.jp/public/2006gl/vol2.html (accessed 31st Jan. 2016), 29 p.

Hammond, G.P., and Jones, C.I. (2008). "Embodied energy and carbon in construction materials", Proc. Institute of Civil Engineers, Energy 161, Issue EN2, 87-98.

IBEF (2016). Cement, India Brand Equity Foundation, http://www.ibef.org/download/Cement_January_ 2016.pdf. (accessed 3rd Feb. 2016).

Indian Bureau of Mines (2015). Indian Minerals Yearbook 2014, Part-III: Mineral Reviews, Cement, Ministry of Mines, Govt. of India, http://ibm.nic.in/writereaddata/files/1218201514339IMYB2014_Cement\%28Adv\%29.pdf (accessed 31st Jan. 2016), 21 p.

Marceau, M., Nisbet, M.A., and VanGeem, M.G. (2006). Life Cycle Inventory of Portland Cement Manufacture, Report SN2095b, Portland Cement Association, Skokie, Illinois, USA, 69 p.

Marceau, M., Nisbet, M.A., and VanGeem, M.G. (2007). Life Cycle Inventory of Portland Cement Concrete, Portland Cement Association, Skokie, Illinois, USA, 121 p. 
Miller, S.A., Horvath, A., Monteiro, P.J.M., and Ostertag, C.P. (2015). "Greenhouse gas emissions from concrete reduced by using mix proportions, geometric aspects, and age as design factors", Environmental Research Letters, 10, doi:10.1088/1748-9326/10/11/114017, 12 p.

PRé Consultants, SimaPro LCA software, https://www.pre-sustainability.com/simapro (accessed 31st Jan. 2016).

Rajya Sabha Secretariat, Parliament of India (2011). Performance of Cement Industry, 95th Report. http://dipp.nic.in/English/ Performance_Cement_Industry.pdf (accessed 31st Jan. 2016), 117 p.

Scrivener, K. (2014). "Options for the future of cement", Indian Concrete J., 88(7), 11-21. 